\title{
Manuel Desviat y la contrarreforma psiquiátrica
}

Desde hace más de treinta años el Dr. Manuel Desviat ha liderado los movimientos de reforma psiquiátrica de este país. Nadie podía pensar, hasta hace unos meses, que acabara siendo también protagonista involuntario de la contrarreforma.

El Dr. Desviat, fundador de esta Revista en 1981 y presidente de la AEN en el período 1993-1997, ha sido la víctima propiciatoria del movimiento de privatización de la sanidad que ha iniciado sin escrúpulos el gobierno autonómico de la Comunidad de Madrid. La transformación del antiguo Hospital Psiquiátrico de Leganés en una red de servicios de salud mental -de la que Manuel Desviat fue artífice y con la que conquistó el aplauso general- se ha visto truncada de la noche a la mañana por quienes han intuido las huellas del negocio en lo que hasta ahora era un servicio público eficiente y prestigioso.

Si Foucault estuviera entre nosotros, a buen seguro le oiríamos decir que primero se persiguió a los moribundos de Leganés y después a los locos, por lo que deben ir remojando sus barbas los extranjeros, los presos y los infecciosos.

Recordemos que los nuevos hospitales de gestión privada que se han puesto en marcha en Madrid lo han hecho sin una población de referencia asignada, ignoran el concepto fundamental de sectorización y dejan libertad absoluta a la libre competencia, mientras que los responsables de los distintos servicios son elegidos por afinidad ideológica y no por sus méritos y experiencia.

La Consejería de Sanidad de Madrid ha hecho trizas la Estrategia en Salud Mental del Sistema Nacional de Salud que ella misma suscribió, se ha cargado la Declaración de Helsinki, ha pisoteado la Ley General de Sanidad y, finalmente, ha puesto en cuarentena al Dr. Desviat y a varios de sus colaboradores por «pérdida de confianza». Todo en la misma tacada. Enhorabuena.

El Consejo de Redacción de la Revista quiere desde estas páginas mostrar su solidaridad con los afectados, condenar los principios de la nueva política sanitaria y animar a sus lectores a levantarse en armas contra quienes han usurpado nuestros principios comunitarios.

¡La Reforma ha terminado! ¡Comienza la contrarreforma! 